\title{
Inorganic Pyrophosphatases: Study of Interest
}

\author{
Mar Papa Daouda1, El Khalfi Bouchra1, Perez-Castiñeira Jose Roman², \\ Serrano Delgado Aurelio ${ }^{2}$, Soukri Abdelaziz ${ }^{1}$ \\ ${ }^{1}$ Laboratory of Physiopathology, Genetics Molecular and Biotechnology (PGMB), Faculty of Sciences Ain Chock, \\ University Hassan II of Casablanca, Casablanca, Morocco \\ ${ }^{2}$ Instituto de Bioquímica Vegetal y Fotosíntesis, CSIC-Universidad de Sevilla, Centro de Investigaciones Científicas \\ "Isla de la Cartuja", Sevilla, Spain \\ Email: ab.soukri@gmail.com
}

How to cite this paper: Daouda, M.P. Bouchra, E.K., Jose Roman, P.-C., Aurelio, S.D. and Abdelaziz, S. (2017) Inorganic Pyrophosphatases: Study of Interest. $A d$ vances in Bioscience and Biotechnology, 8 , 388-397.

https://doi.org/10.4236/abb.2017.810028

Received: August 21, 2017

Accepted: October 28, 2017

Published: October 31, 2017

Copyright $\odot 2017$ by authors and Scientific Research Publishing Inc. This work is licensed under the Creative Commons Attribution International License (CC BY 4.0).

http://creativecommons.org/licenses/by/4.0/

\begin{abstract}
Inorganic pyrophosphatases are enzymes that catalyze the hydrolysis of inorganic pyrophosphate to orthophosphate. These enzymes are divided into two groups: the soluble pyrophosphatases and the membrane pyrophosphatases. They vary in structure and each has a determined catalysis mechanism. Soluble pyrophosphatases are ubiquitous enzymes and play a key role in regulating the rate of pyrophosphate and balance in this sense, the biosynthetic reactions. Membrane pyrophosphatases are ion pumps, producing a proton or sodium gradient, and provide critical energy reserves to organisms, especially during stress conditions. Several studies have shown that these enzymes are involved in numerous disorders (diseases, fault cell growth...). However they are potential targets for the development of agents against parasites. This article consists of a description of the different types, structures, catalytic properties of inorganic pyrophosphatases and their involvement in cellular metabolism.
\end{abstract}

\section{Keywords}

Pyrophosphatases, Structure, Catalytic Activity, Phylogeny, Pathology

\section{Introduction}

Phosphorus (P) is the fifth largest bio-element to living organisms as a compound cell. It is transported within cells as orthophosphate anion $\left(\mathrm{H}_{2} \mathrm{PO}_{4}^{-}\right.$or inorganic phosphate) and it is involved in the formation of phospholipids, components with high energy (ATP) and pathways subtracts like pyrophosphate $\left(\mathrm{PO}_{3}^{2-}-\mathrm{O}-\mathrm{PO}_{3}^{2-}\right)$, whose binding energy is used by all organisms.

In humans, inorganic phosphate is located mainly in bones (85\%), $14 \%$ in 
intracellular and a small percentage (1\%) in extracellular fluid [1]. Phosphorus is also an essential nutrient in plants growth. In microorganisms, inorganic phosphate plays a key role in the cycle of cell development [2]. In industrial applications, inorganic phosphate is widely used in cleaning products, textile processing, toothpaste, water treatment, horticulture fertilizers and fire extinguishers [3].

Intracellular level of pyrophosphate is permanently regulated by hydrolysis in orthophosphate. This reaction is catalyzed by inorganic pyrophosphatases. Two major types of inorganic pyrophosphatase are distinguished: the soluble pyrophosphatases (sPPases) and the membrane pyrophosphatases $\left(\mathrm{H}^{+} / \mathrm{Na}^{+}\right.$-PPases). These enzymes are essential for regulating intracellular level of pyrophosphate and producing a proton or sodium gradient necessary for cells.

This article will describe the different types, structures, catalytic properties of inorganic pyrophosphatases and their involvement in cellular metabolism.

\section{Inorganic Pyrophosphate}

Pyrophosphate is a byproduct of several synthetic pathways (nucleic acids, proteins, polysaccharides,) which makes this compound of a large interest. Pyrophosphate is a molecule composed of two orthophosphate groups linked by a phosphoanhydride bond. It is a chemical moiety wherein is stored a fundamental binding energy for the cell's energy needs. This is a molecule whose hydrolysis is energetically favorable and is obtained commercially by dehydration under heating of orthophosphate. The first described reaction in which pyrophosphate is involved is the formation of ATP (Adenosine Tri Phosphate) and NMN (Nicotinamide Mono Nucleic) in the presence of $\mathrm{NAD}^{+}$and pyrophosphate [4]. Since then, the involvement of pyrophosphate has been described in many biosynthetic reactions.

However, pyrophosphate is considered a by-product of cellular anabolism whose subsequent hydrolysis indicates that anabolic reactions occur in the right direction [5]. The cellular level of inorganic pyrophosphate must be regulated and an eventual disruption of the metabolism of inorganic pyrophosphate may be associated with various diseases [6].

\section{Inorganic Pyrophosphatase: Overview}

The enzymes that hydrolyze inorganic pyrophosphate to orthophosphate are called inorganic pyrophosphatases (PPases) and they have been discovered for the first time in animal tissues [7]. They are divided in two major groups: pyrophosphatases soluble (sPPases) and membrane pyrophosphatases $\left(\mathrm{H}^{+} / \mathrm{Na}^{+}-\mathrm{PPases}\right)$. These two enzymes are not homologous and have amino acid sequences and very different structures, but have patterns appearing in the sequences corresponding to the catalytic site [8].

\subsection{Soluble Pyrophosphatases}

Soluble pyrophosphatases (sPPases) are ubiquitous enzymes which play an im- 
portant role in the metabolism of phosphorus. The sPPases catalyze the hydrolysis of inorganic pyrophosphate produced in the metabolic pathways in two orthophosphate molecules. Namely by their nature and their omnipresence, the sPPases play a central role in the metabolic reactions, because in their absence, the accumulation of PPi produces dysfunction of metabolic reactions [9] [10]. The hydrolysis of $\mathrm{PPi}$ is therefore important to provide the Pi necessary for phosphorylation, and allow the smooth running of biosynthetic reactions [11]. There are three families of sPPases: families I and II are non homologous. Family III is unexplored and found in some bacterial species. The latter seems to be modified to dehalogenase of haloalkanes, which operate by a separate mechanism [12].

The sPPases family I are usually found in most eukaryotes, archaea and bacteria, while the family II enzymes are found in some bacteria, archaea and primitive eukaryotes. These two families are distinguished firstly by their activation cofactor: the sPPases family I is mainly $\mathrm{Mg}^{2+}$ as cofactor, while sPPases Family II work with the $\mathrm{Mn}^{2+}$ as cofactor [13] [14]. In addition, it is shown that some sPPases (yeasts, animals, and bacteria) are strongly inhibited by $\mathrm{Ca}^{2+}$ at very low physiological concentrations [15] [16]. Others are activity dependent on calcium, particularly in Leishmania major (LmsPPase) [17]. Secondly, the sequences of both sPPases are not similar. However, the active site of the two proteins is retained, meaning a possible common ancestor of these two enzymes [13] [18].

\subsection{Membrane Pyrophosphatases}

From an architectural and functional point of view, membrane pyrophosphatases are completely different. They are ion pumps, found in plants, algae, some protozoa, bacteria and archaea. They produce reversible reactions which coupling the hydrolysis-energy of $\mathrm{PPi}$ and proton $\left(\mathrm{H}^{+}\right.$-PPases) or sodium $\left(\mathrm{Na}^{+}-\mathrm{PPases}\right)$ [19]. The $\mathrm{H}^{+}$-PPases are found in prokaryotes (acidocalcisomes vesicles) [20] [21], eukaryotes and protists (vacuolar membranes of plants, protists acidocalcisomales membranes) [22] [23]. The $\mathrm{H}^{+}$-PPases are present in all domains of life and provide to host important energy reserves, especially during stress conditions (drought, nutrient deficiency, anoxia, cold stress, low light intensity, stress salt) and lack of energy [21] [24]. The $\mathrm{Na}^{+}-$PPases are only found in prokaryotes [19].

Membrane pyrophosphatases can be classified according to their specific ion to pump $\left(\mathrm{Na}^{+}\right.$and/or $\left.\mathrm{H}^{+}\right)$and their dependent activation on $\mathrm{K}^{+}$[19] [25] [26].

\section{Structure of Inorganic Pyrophosphatases}

\subsection{Soluble Pyrophosphatases}

The first pyrophosphatase crystallized structure is described in 1952 and belong to the sPPases family I [27]. The two best examples of studies of sPPases family I are hexameric sPPase Escherichia coli (E-PPase) and dimeric sPPase Saccharo- 
myces cerevisiae (Y-PPase), as prokaryotic and eukaryotic models respectively, including their structure and mechanism which have been well characterized [28] [29]. The sPPases family I are formed in a single compact structure, the center which contains the active site consists of five preserved $\beta$ strands [30] (Figure 1). The eukaryotic sPPases are generally dimeric [28] while bacterial sPPases are generally hexameric [31]. Eukaryotic sPPases are larger than bacteria sPPases (280 residues against 170 residues), this is explained by the fact that the eukaryotic enzyme (Saccharomyces cerevisiae PPase, Figure 1) has an external $\beta$ strand and extensions in $\mathrm{N}$ and $\mathrm{C}$ terminal to the base structure.

The structure of soluble pyrophosphate family II is described later and they are well characterized in Bacillus subtilis and recently in Staphylococcus aureus [18] [32]. They are different to sPPases family I and they consist of two homodimeric domains whose active site is located at the interface (Figure 1).

\subsection{Membrane Pyrophosphatases}

The structure of these enzymes is established for the first time in studies on membrane pyrophosphatases of Mung bean (VrPPase) and Thermotoga maritima (TmPPase) [33] [34]. Membrane PPases consist of a single large transmembrane domain, with $15-17$ transmembrane helices with hydrophilic regions within these proteins [35]. Membrane PPases are homodimeric although the active site is located in a single monomer [34]. The basic structure of these functional ion pumps contains six central helices. There are four catalytic regions such as hydrolysis center, a space for coupling, a gateway ions formed by charged residues and a way out to the periplasmic side of the membrane.

\section{Catalytic Activity of Pyrophosphatases}

\subsection{Soluble Pyrophosphatases}

Hydrolysis by sPPases requires three or four metals, depending on the family of the enzyme, $\mathrm{pH}$ and the concentration of PPi [37] [38]. The hydrolysis reaction is based on the activation of a nucleophile group, the generation of a nucleophilic

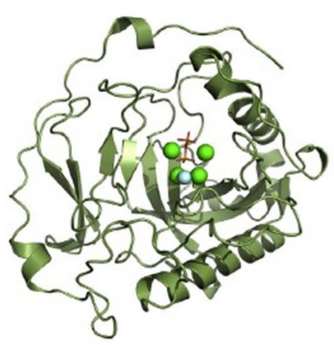

(a)

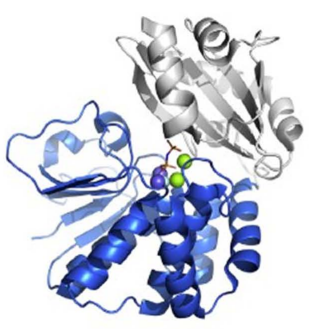

(b)

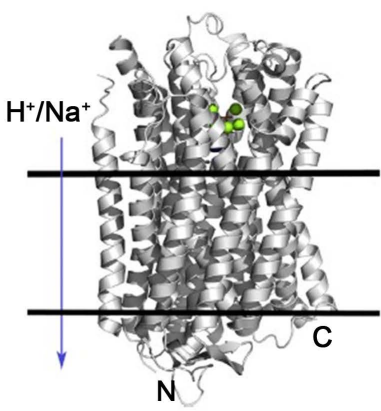

(c)

Figure 1. Overview of the conformation of the substrate with different PPases [36]. ((a) Family I Saccharomyces cerevisiae PPase; (b) Family II Bacillus subtilis PPase; (c) Membrane Mung bean PPase). Black lines in (c) mean lipid bilayer, the arrow shows the cytoplasmic side. 
attack and hydrolysis is carried out without intermediate enzyme-phosphate [33] [39]. A crucial difference between sPPases in pyrophosphate hydrolysis term is the response of both enzymes (family I and family II sPPases) with different inhibitors, especially fluroride and diphosphonates.

The pyrophosphate hydrolysis mechanism by sPPases Family I consists of a nucleophilic attack of a water molecule on a half electrophilic phosphate from pyrophosphate (Figure 2 and Figure 3). This mechanism is well described in Escherichia coli, provided by three divalent metal ions located in the catalytic site of the enzyme: M1 and M2 ions present before the substrate binding site, they are involved in the positioning of the substrate and the activating of a water molecule for the nucleophilic attack; M3 ion coordinates the positioning of pyrophosphate in the active site [12].

The active site containing a water molecule (Wc) and the divalent metal ion M2: a) that captures pyrophopshate PPi with the M1 and M3 ions; b) The nucleophile complex formed following proton-abstraction by an aspartate residue Asp (Asp 67 in the PPase from Escherichia coli, Asp54 in the PPase from Mtb tuberculosis) attack the electrophilic active phosphate group of PPi; c) upon hydrolysis; d) a new water molecule binds phosphate and the other group dissociates, giving a complex that releases the phosphate $(\mathrm{Pi})$ attacked [12].

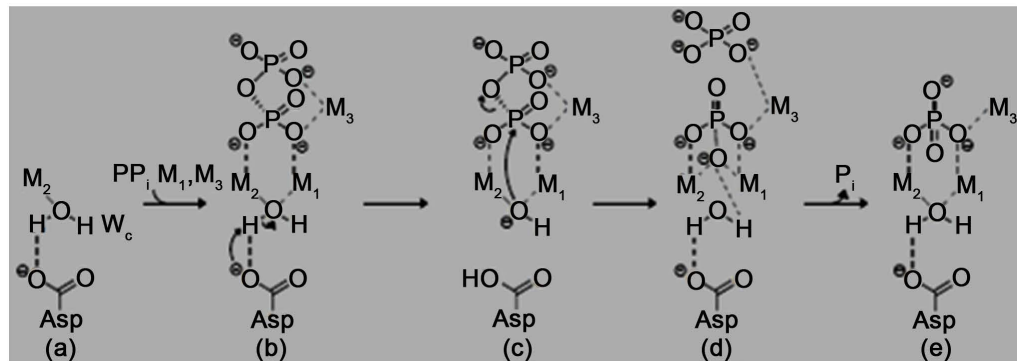

Figure 2. Hydrolysis mechanism of family I PPases [12].

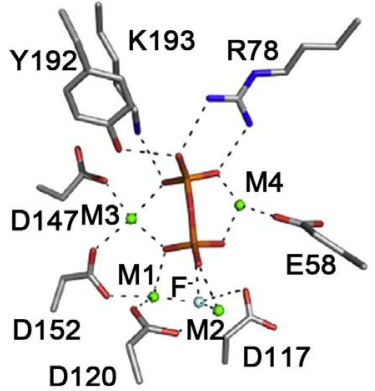

(a)

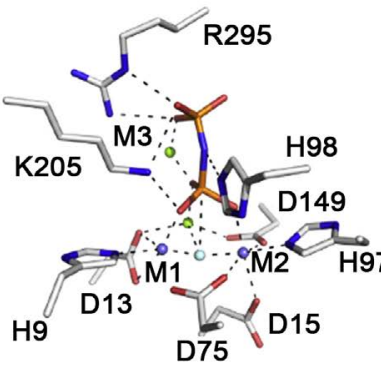

(b)

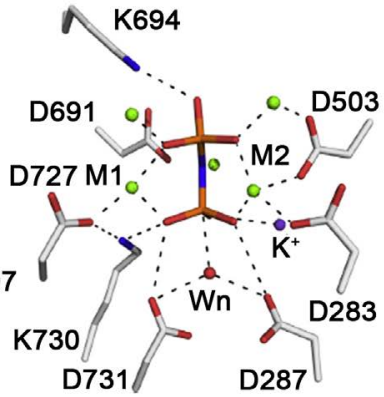

(c)

Figure 3. Active site comparison of different pyrophosphatase [36]. (a) sPPases Family I (Saccharomyces cerevisiae); (b) sPPase Family II (Bacillus subtilis); (c) membrane PPases (Mung bean). The hydrolysis binding site is vertical in the three cases with the nucleophilic below, color atoms represent the $\mathrm{Mg}^{2+}$ (green), $\mathrm{Mn}^{2+}$ (light purple), $\mathrm{K}^{+}$(purple). The nucleophilic water molecule is named $\mathrm{Wn}$ and represented by the red atom in $\mathrm{c}$; the electrophilic phosphorus is at the bottom of each figure. Hydrogen bonds and ionic interactions are represented by the dashed [36]. 
The first structures of sPPases family II, described in Bacillus subtilis and Streptococcus mutans, showed on the catalytic mechanism that two ions (M1 and M2) of the enzyme coordinate with the substrate and a third ion (M3) which does not directly interact with the protein [18] [40]. A recent study in Bacillus subtilis shows a fourth ion (M4) involved in the coordination of the enzyme-substrate complex [27]. In fact, the three ions M1, M2 and M4 bound to the substrate and position the nucleophilic water molecule for catalytic attack.

\subsection{Membrane Pyrophosphatases}

In catalytic term the hydrolysis power of membrane pyrophosphatases is lower than soluble pyrophosphatases. The water molecule contained in the active site has a low anionic retention power, PPi is captured in a metal cage and its hydrolysis is generated by the ion gradient pumped by the protein, which modifies the overall charge [36].

\section{Phylogenic Trees of Pyrophosphatases}

Inorganic pyrophosphatases are widely distributed in living organisms. Several studies have drawn up phylogenetic trees to classify these enzymes following the differences in their amino acid sequences. An example of a relevant study on membrane pyrophosphatases is the phylogenetic comparative analysis of the $\mathrm{H}^{+}$-Pases of protozoa and other species [41].

Another pertinent example on soluble pyrophosphatases was Gomez Garcia et al. study [42], which consists of molecular phylogenetic analysis of two eukaryotic sPPases family I isolated from Chlamydomonas reinhardtii and other prokaryotic, protists, fungi and metazoans sPPases. The phylogenetic tree showed a broad distribution of soluble pyrophosphatases among bacteria, archeae, animals, fungi and plants. These two sPPases had different molecular phylogenies, the first is closely related to other eukaryotic sPPases while the second resembles to prokaryotic sPPases [42].

\section{Interest of Pyrophosphatases Study}

Inorganic pyrophosphate is suggested as the predecessor of ATP in the early stages of evolution and as an alternative to provide energy in some modern cells [20]. It is a byproduct of several metabolic pathways, and it was shown that the cell rate is regulated continuously, and dysfunction of this control can be at the origin of several anomalies [6]. Inorganic pyrophosphatase are enzymes which play an important role in cellular metabolism by hydrolyzing pyrophosphate. Since their discovery, several interesting studies were performed showing the importance of these enzymes on cellular metabolism. Soluble pyrophosphatase are essential to metabolic reactions of bacteria and yeast [10] [29]. They are involved on the growth of bacteria such as Escherichia coli. Indeed deficiency of these enzymes could affect the growth of some organizations, such as the involvement of the defective pyrophosphatase in the curbed development and cell 
death cycle of yeast fermentation [43]. Likewise, it is shown that the soluble pyrophosphatases are overexpressed in breast cancer [44]. Studies on the structure of pyrophosphatases are also important because understanding the structure and function of these enzymes is bio-medically important, like family pyrophosphatases II which are specific to certain pathogens such as Staphylococcus aureus, Streptococcus agalactiae, Streptococcus mutans and Bacillus anthracis. They could be potential targets for the discovery and development of new antibacterial products [32].

Membrane pyrophosphatases are known as ion pumps that combine the translocation of $\mathrm{H}^{+}$ions or $\mathrm{Na}^{+}$ions to the hydrolysis of PPi and are a real source of biological energy [45]. They are generally found in plants and protists, often in conditions of stress, limited energy, frequent enough to provide an ion gradient when ATP is almost absent [17] [21]. These membrane enzymes do not seem to be present in mammals but could be potential targets for drugs and vaccines against pathogenic protists. Most of them have an intracellular lifestyle. The study on the mode of regulation of these enzymes regarding the protein level as well as at the genomic level could be of importance to biomedical field and will provide better understanding of certain phenomena of cell metabolism.

\section{References}

[1] Goldman, L. and Ausiello, D. (2007) Cecil Medicine. 23rd Edition, Saunders Elsevier, Philadelphia, PA.

[2] Boer, V.M., Amini, S. and Botstein, D. (2008) Influence of Genotype and Nutrition on Survival and Metabolism of Starving Yeast. Proceedings of the National Academy of Sciences of the United States of America, 105, 6930-6935. https://doi.org/10.1073/pnas.0802601105

[3] Weiner, M.L., Salminen, W.F., Larson, P.R., Barter, R.A., Kranetz, J.L. and Simon, G.S. (2001) Toxicological Review of Inorganic Phosphates. Food and Chemical Toxicology, 39, 759-786.

[4] Kornberg, A. (1948) Participation of Inorganic Pyrophosphate in the Reversible Enzymatic Synthesis of Diphosphopyridine Nucleotide. Journal of Biological Chemistry, 176, 1475-1476.

[5] Lahti, R., Pitkäranta, T., Valve, E., Ilta, I., Kukko-kalske, E. and Heinonen, J. (1988) Cloning and Characterization of the Gene Encoding Inorganic Pyrophosphatase of Escherichia coli K-12. Journal of Bacteriology, 170, 5901-5907. https://doi.org/10.1128/jb.170.12.5901-5907.1988

[6] Terkeltaub, R.A. (2001) Inorganic Pyrophosphate Generation and Disposition in Pathophysiology. American Journal of Physiology_Cell Physiology, 281, C1-C11.

[7] Kay, H.D. (1928) The Phosphatases of Mammalian Tissues: Pyrophosphatase. Biochemical Journal, 22, 1446-1448. https://doi.org/10.1042/bj0221446

[8] Rea, P.A. and Poole, R.J. (1993) Vacuolar $\mathrm{H}^{+}$-Translocating Pyrophosphatase. Annual Review of Plant Physiology and Plant Molecular Biology, 44, 157-180. https://doi.org/10.1042/bj0221446

[9] Kukko-Kalske, E. and Heinonen, J. (1985) Inorganic Pyrophosphate and Inorganic Pyrophosphatase in Escherichia Coli. The International Journal of Biochemistry, 17, 575-580. 
[10] Chen, J., Brevet, A., Fromant, M., Lévêque, F., Schmiter, J.M., Blanquet, S. and Plateau, P. (1990) Pyrophosphatase Is Essential for Growth of Escherichia coli. Journal of Bacteriology, 172, 5686-5689. https://doi.org/10.1128/jb.172.10.5686-5689.1990

[11] Perez-Castineira, J.R., Lopez-Marques, R.L., Villalba, J.M., Losada, M. and Serrano, A. (2002) Functional Complementation of Yeast Cytosolic Pyrophosphatase by Bacterial and Plant $\mathrm{H}^{+}$-Translocating Pyrophosphatases. Proceedings of the National Academy of Sciences USA, 99, 15914-15919.

https://doi.org/10.1073/pnas.242625399

[12] Pratt, A.C., Dewage, S.W., Pang, A.H., Biswas, T., Barnard-Britson, S., Cisneros, G.A. and Tsodikov, O.V. (2015) Structural and Computational Dissection of the Catalytic Mechanism of the Inorganic Pyrophosphatase from Mycobacterium Tuberculosis. Journal of Structural Biology, 192, 76-87.

https://doi.org/10.1016/j.jsb.2015.08.010

[13] Parfenyev, A.N., Salminen, A., Halonen, P., Hachimori, A., Baykov, A.A. and Lahti, R. (2001) Quaternary Structure and Metal Ion Requirement of Family II Pyrophosphatases from Bacillus subtilis, Streptococcus gordonii, and Streptococcus mutans. The Journal of Biological Chemistry, 276, 24511-24518. https://doi.org/10.1074/jbc.M101829200

[14] Zyryanov, A.B., Vener, A.V., Salminen, A., Goldman, A., Lahti, R. and Baykov, A.A. (2004) Rates of Elementary Catalytic Steps for Different Metal Forms of the Family II Pyrophosphatase from Streptococcus gordonii. Biochemistry, 43, 1065-1074. https://doi.org/10.1021/bi0357513

[15] Felix, H. and Fleisch, H. (1975) Properties of Inorganic Pyrophosphatase of Pig Scapula Cartilage. Biochemical. Journal, 147, 111-118.

[16] Yang, Z. and Wensel, T.G. (1992) Inorganic Pyrophosphatase from Bovine Retinal Rod Outer Segments. The Journal of Biological Chemistry, 267, 24634-24640.

[17] Gomez-Garcia, M.R., Ruiz-Pereza, L.M., Gonzalez-Pacanowskaa, D. and Serrano, A. (2004) A Novel Calcium-Dependent Soluble Inorganic Pyrophosphatase from the Trypanosomatid Leishmania major. FEBS Letters, 560, 158-166. https://doi.org/10.1016/S0014-5793(04)00097-3

[18] Ahn, S., Milner, A.J., Futterer, K., Konopka, M., Ilias, M., et al. (2001) The "Open” and "Closed" Structures of the Type-C Inorganic Pyrophosphatases from Bacillus subtilis and Streptococcus gordonii. Journal of Molecular Biology, 313, 797-811. https://doi.org/10.1006/jmbi.2001.5070

[19] Luoto, H.H., Baykov, A.A., Lahti, R. and Malinen, A.M. (2013) Membrane Integral Pyrophosphatase Subfamily Capable of Translocating Both $\mathrm{Na}^{+}$and $\mathrm{H}^{+}$. Proceedings of the National Academy of Sciences USA, 110, 1255-1260.

https://doi.org/10.1073/pnas.1217816110

[20] Perez-Castiñeira, J.R., Lopez-Marques, R.L., Losada, M. and Serrano, A. (2001) A Thermostable $\mathrm{K}^{+}$-Stimulated Vacuolar-Type Pyrophosphatase from the Hyperthermophilic Bacterium Thermotoga maritima. FEBS Letters, 496, 6-11. https://doi.org/10.1016/S0014-5793(01)02390-0

[21] Maeshima, M. (2000) Vacuolar $\mathrm{H}^{+}$-Pyrophosphatase. Biochimica et Biophysica Acta, 1465, 37-51. https://doi.org/10.1016/S0005-2736(00)00130-9

[22] Gaxiola, R.A., Palmgren, M.G. and Schumacher, K. (2007) Plant Proton Pumps. FEBS Letters, 581, 2204-2214. https://doi.org/10.1016/j.febslet.2007.03.050

[23] McIntosh, M.T. and Vaidya, A.B. (2002) Vacuolar Type $\mathrm{H}^{+}$Pumping Pyrophosphatases of Parasitic Protozoa. International Journal for Parasitology, 32, 1-14. 
https://doi.org/10.1016/S0020-7519(01)00325-3

[24] Serrano, A., Pérez-Castiñeira, J.R., Baltscheffsky, M. and Baltscheffsky, H. (2007) $\mathrm{H}^{+}$-PPases: Yesterday, Today and Tomorrow. IUBMB Life, 59, 76-83. https://doi.org/10.1080/15216540701258132

[25] Belogurov, G.A. and Lahti, R. (2002) A Lysine Substitute for K+ A460K Mutation Eliminates $\mathrm{K}^{+}$Dependence in $\mathrm{H}^{+}$-Pyrophosphatase of Carboxydothermus hydrogenoformans. The Journal of Biological Chemistry, 277, 49651-49654. https://doi.org/10.1074/jbc.M210341200

[26] Malinen, A.M., Belogurov, G.A., Baykov, A.A. and Lahti, R. (2007) $\mathrm{Na}^{+}$-Pyrophosphatase: A Novel Primary Sodium Pump. Biochemistry, 46, $8872-8878$. https://doi.org/10.1021/bi700564b

[27] Kunitz, M. (1952) Crystalline Inorganic Pyrophosphatase Isolated from Baker's Yeast. The Journal of General Physiology, 35: 423-450. https://doi.org/10.1085/jgp.35.3.423

[28] Cooperman, B.S., Baykov, A.A. and Lahti, R. (1992) Evolutionary Conservation of the Active Site of Soluble Inorganic Pyrophosphatase. Trends in Biochemical Sciences, 17, 262-266. https://doi.org/10.1016/0968-0004(92)90406-Y

[29] Lundin, M., Baltscheffsky, H. and Ronne, H. (1991) Yeast PPA2 Gene Encodes a Mitochondrial Inorganic Pyrophosphatase That Is Essential for Mitochondrial Function. The Journal of Biological Chemistry, 266: 12166-12168.

[30] Heikinheimo, P., Lehtonen, J., Baykov, A.A., Lahti, R., Cooperman, B.S. and Goldman, A. (1996) The Structural Basis for Pyrophosphatase Catalysis. Structure, 4, 1491-1508. https://doi.org/10.1016/S0969-2126(96)00155-4

[31] Josse, J. and Wong, S.C.K. (1971) 20 Inorganic Pyrophosphatase of Escherichia coli. The Enzymes, 4, 499-527. https://doi.org/10.1016/S1874-6047(08)60380-7

[32] Gajadeera, C.S., Zhang, X., Wei, Y. and Tsodikov, O.V. (2015) Structure of Inorganic Pyrophosphatase from Staphylococcus aureus Reveals Conformational Flexibility of the Active Site. Journal of Structural Biology, 189, 81-86.

https://doi.org/10.1016/j.jsb.2014.12.003

[33] Lin, S.M., Tsai, J.Y., Hsiao, C.D., Huang, Y.T., Chiu, C.L., et al. (2012) Crystal Structure of Membrane-Embedded $\mathrm{H}^{+}$-Translocating Pyrophosphatase. Nature, 484, 399-403. https://doi.org/10.1038/nature10963

[34] Kellosalo, J., Kajander, T., Kogan, K., Pokharel, K. and Goldman, A. (2012) The Structure and Catalytic Cycle of a Sodium Pumping Pyrophosphatase. Science, 337, 473-476. https://doi.org/10.1126/science.1222505

[35] Mimura, H., Nakanishi, Y., Hirono, M. and Maeshima, M. (2004) Membrane Topology of the $\mathrm{H}^{+}$-Pyrophosphatase of Streptomyces coelicolor Determined by Cysteine-Scanning Mutagenesis. The Journal of Biological Chemistry, 279, 35106-35112. https://doi.org/10.1074/jbc.M406264200

[36] Kajander, T., Kellosalo, J. and Goldman, A. (2013) Inorganic Pyrophosphatases: One Substrate, Three Mechanisms. FEBS Letters, 587, 1863-1869. https://doi.org/10.1016/j.febslet.2013.05.003

[37] Fabrichniy, I.P., Lehtio, L., Tammenkoski, M., Zyryanov, A.B., Oksanen, E., et al. (2007) A Trimetal Site and Substrate Distortion in a Family II Inorganic Pyrophosphatase. The Journal of Biological Chemistry, 282, 1422-1431. https://doi.org/10.1074/jbc.M513161200

[38] Baykov, A.A. and Shestakov, A.S. (1992) Two Pathways of Pyrophosphate Hydroly- 
sis and Synthesis by Yeast Inorganic Pyrophosphatase. European Journal in Biochemistry, 206, 463-470. https://doi.org/10.1111/j.1432-1033.1992.tb16947.x

[39] Baykov, A.A., Kasho, V.N., Bakuleva, N.P. and Rea, P.A. (1994) Oxygen Exchange Reactions Catalyzed by Vacuolar $\mathrm{H}^{+}$-Translocating Pyrophosphatase. FEBS Letters, 350, 323-327. https://doi.org/10.1016/0014-5793(94)00800-0

[40] Merckel, M.C., Fabrichniy, I.P., Salminen, A., Kalkkinen, N., Baykov, A.A., et al. (2001) Crystal Structure of Streptococcus mutans Pyrophosphatase: A New Fold for an Old Mechanism. Structure, 9, 289-297. https://doi.org/10.1016/S0969-2126(01)00587-1

[41] Perez-Castineira, J.R., Alvar, J., Ruis-Pérez, L.M. and Serrano, A. (2002) Evidence for a Wide Occurrence of Proton-Translocating Pyrophosphatase Genes in Parasitic and Free-Living Protozoa. Biochemical and Biophysical Research Communications, 294, 567-573. https://doi.org/10.1016/S0006-291X(02)00517-X

[42] Gomez-Garcia, M.R., losada, M. and Serrano, A. (2006) A Novel Subfamily of Monomeric Inorganic Pyrophosphatases in Photosynthetic Eukaryotes. Biochemical Journal, 395, 211-221. https://doi.org/10.1042/BJ20051657

[43] Serrano-Bueno, G., Hernandez, A., Lopez-Lluch, G., Perez-Castineira, J.R., Navas, P. and Serrano, A. (2013) Inorganic Pyrophosphatase Defects Lead to Cell Cycle Arrest and Autophagic Cell Death through NAD+ Depletion in Fermenting Yeast. The Journal of Biological Chemistry, 288, 13082-13092. https://doi.org/10.1074/jbc.M112.439349

[44] Hamler, R.L., Zhu, K., Buchanan, N.S., Kreunin, P., Kachman, M.T. and Miller, F.R. (2004) A Two-Dimensional Liquidphase Separation Method Coupled with Mass Spectrometry for Proteomic Studies of Breast Cancer and Biomarker Identification. Proteomics, 4, 562-577. https://doi.org/10.1002/pmic.200300606

[45] Baltscheffsky, M., Schultz, A. and Baltscheffsky, H. (1999) $\mathrm{H}^{+}$-PPases: A Tightly Membrane-Bound Family. FEBS Letters, 457, 527-533.

https://doi.org/10.1016/S0014-5793(99)90617-8 